\title{
A Patient Bill of Rights for Psychotropic Prescription: A Call for a Higher Standard of Care
}

\author{
Barry L. Duncan ${ }^{1}$, David O. Antonuccio ${ }^{2}$ \\ ${ }^{1}$ Heart and Soul of Change Project, Jensen Beach, USA; ${ }^{2}$ School of Medicine, University of Nevada, Reno, USA; Fielding Graduate \\ University, Santa Barbara, USA. \\ Email: barrylduncan@comcast.net,oliver2@aol.com
}

Received June 28 ${ }^{\text {th }}$, 2011; revised July 20 ${ }^{\text {th }}$ 2011; accepted August 25 ${ }^{\text {th }}, 2011$.

\begin{abstract}
The pharmaceutical industry has made it very difficult to know what the clinical trial evidence actually is regarding psychotropics. Consequently, primary care physicians and other front-line practitioners are at a disadvantage when attempting to adhere to the ethical and scientific mandates of evidence based prescriptive practice. This article calls for a higher standard of prescriptive care derived from a risk/benefit analysis of clinical trial evidence. The authors assert that current prescribing practices are often empirically unsound and unduly influenced by pharmaceutical company interests, resulting in unnecessary risks to patients. In the spirit of evidenced based medicine's inclusion of patient values as well as the movement toward health home and integrated care, we present a patient bill of rights for psychotropic prescription. We then offer guidelines to raise the bar of care equal to the available science for all prescribers of psychiatric medications.
\end{abstract}

Keywords: Psychotropics, Risk/Benefit Analysis, Patient Rights, Primary Care Physicians, Pharmaceutical Company Influence

\section{Introduction}

Largely because of the unprecedented marketing by the pharmaceutical industry as well as the transition of behavioral health to primary care venues, spending for psychiatric medications in the US increased from nearly $\$ 8$ billion in 1997 to $\$ 20$ billion in 2004 [1], reaching over $\$ 40$ billion in sales in 2010 [2]. Concurrently, the use of psychotherapy has declined [3] and community behavioral intervention has fallen or remained flat [4].

Are these patterns justified by the clinical trial evidence? Unfortunately, the pharmaceutical companies have made it very difficult for everyday practitioners to have an accurate picture of the trial data. Marcia Angell, former editor of the New England Journal of Medicine concludes:

It is simply no longer possible to believe much of the clinical research that is published, or to rely on the judgment of trusted physicians or authoritative medical guidelines. I take no pleasure in this conclusion, which I reached slowly and reluctantly over my two decades as an editor of The New England Journal of Medicine” [5].
The vast reach of the pharmaceutical industry in psychotropic prescription practices extends to the Internet, print, and broadcast media, direct-to consumer-advertising, "grassroots" consumer-advocacy organizations, professsional guilds, medical schools, prescribing physicians, and research-even into the board rooms of the FDA [5,6]. Antonuccio et al. conclude, "It is difficult to think of any arena involving information about medications that does not have significant industry financial or marketing influences.” [6] Given the infiltration of industry influence, relying on press reports, web pages, and even the academic literature can be misleading as a basis for sound clinical decisions.

Compounding the problem, primary care and other front line practitioners often do not have the time, formal education, and training to properly evaluate the clinical trial literature, or to know the range of treatment options available to permit matching with patient preferences. The unfortunate result is an over reliance on psychotropics as a first line intervention and an under-reliance on safer and comparably effective psychosocial options. 
Building on earlier efforts to establish patient informed consent regarding psychotropics [7,8], this article calls for a higher standard of prescriptive care derived from a risk/benefit analysis of clinical trial evidence $[9,10]$. The authors assert that many current prescribing practices are empirically unsound and unduly influenced by pharmaceutical company interests, which tend to inflate benefits and minimize risk.

In the spirit of evidenced based medicine's inclusion of patient values as well as the movement toward health home (i.e., an approach to providing comprehensive primary care that emphasizes physician/patient collaboration), we present a patient bill of rights for psychotropic prescription. The Bill of Rights is the name of the first ten amendments to the U.S. Constitution introduced by James Madison to the First U.S. Congress in 1789. The Bill of Rights limits the power of the U.S. Federal Government, protecting the natural rights of liberty and property, including freedom of speech, free press, free assembly, and freedom from cruel and unusual punishment. This article proposes a bill of rights designed to preserve the autonomy and freedom of patients who are prescribed psychotropic drugs in the hopes of creating an evolving document and ongoing discussion of this critical issue. We then offer guidelines to raise the bar of care equal to the available science for all prescribers of psychiatric medications.

\section{A Patient Bill of Rights for Psychotropic Prescription}

\subsection{Patients Have a Right to a Thorough Diagnostic and Functional Assessment by a Behavioral Health Care Specialist}

While diagnosis is critical to providing evidence based medical treatment, diagnosis in behavioral healthcare arising from the Diagnostic and Statistical Manual of the American Psychiatric Association has notoriously poor reliability and validity [11]. An over-reliance on this descriptive, symptom-based diagnostic view can lead to a "pill for every ill" prescriptive practice [12]. More important than a diagnostic label is an assessment of how a patient's problems impact his or her life [13] and what can be done about it [14]. Closely aligned with a health home perspective and integrated care, a thorough and systematic assessment gathers information from all significantly involved persons and includes developmental, environmental, familial, and socio-cultural understandings of both problems and solutions. Given that up to $50 \%$ of patients referred for mental health services do not make the first appointment [15], it is arguably best that the assessment and treatment be a part of routine care rather than conducted elsewhere. When they are, benefits ensue. For example, a recent meta-analysis reported improvements in both mental and physical health when brief psychotherapy was incorporated into primary care settings to treat anxiety and depression [16].

A thorough assessment includes the possibility that the problem(s) in question may be best described as part of the human condition or a natural response to the stress of life, particularly poverty and injustice, or in other words, the right not to have normal behavior labeled as pathological. Pharmaceutical marketing has led to what has been called "disease mongering," or the creation or expansion of disorders to increase revenues of a for-profit industry [17]. For example, a recent study compared the number of visits of patients diagnosed with bipolar disorder for ages 0 - 19 for the years 1994-1995 and 20022003 [18]. Investigators found a 40-fold increase in visits for this diagnosis, a questionable increase despite the ostensible explanation of advances in detection of a heretofore undetected illness. Of these patients diagnosed with bipolar disorder, more than $90 \%$ were treated with psychoactive medications, approximately one half given an antipsychotic and one third given an anticonvulsant. Despite the fact that no evidence supports polypharmacy with youth, most were prescribed more than one medication, and only 4 out of 10 received psychotherapy. A thorough assessment starts with an understanding of the patient within the realm of normal human behavior.

\subsection{Patients Have a Right to Be Informed about the Safety and Efficacy of Treatment Options Including Psychological Treatment Alone, Medication Alone, Psychological Treatment Combined with Medication, as Well as No Treatment}

The risks and benefits of any intervention should be transparently discussed. Such open discussions allow patients to decide which treatment offers the best option in line with their own values and cultural contexts [8]. For example, parents of children struggling with depresssion can be shown the efficacy and safety data about cognitive behavioral therapy (CBT) vs. antidepressant treatment, alone or in combination. CBT alone had comparable outcome at 30 weeks while the antidepressant treatment groups had significantly more psychiatric adverse events; six suicide attempts occurred in the medication groups $\mathrm{v}$. one in the nonmedication group [10, 19-21]. Similarly, patients should be informed about recent meta-analytic data showing that antidepressants are not more effective than placebo except for a small portion of patients in the very severe range [22,23]. Paradoxically, despite the growing evidence of the minimal therapeutic effects of antidepressants, sales for them increased in 2010 in the US [2] Concomitant to a risk/ 
benefit discussion, patients should be informed about the likely outcome of no treatment at all. Problems or conditions often improve without intervention. With depresssion, for example, spontaneous remission ranges from $20 \%$ to $60 \%$ for any given episode $[24,25]$.

As part of a risk/benefit discussion, patients also should be informed that medical science has yet to reliably identify any biological markers or chemical imbalances for any psychiatric diagnosis [12,26]. Similarly, there is no evidence that any psychotropic medications repair chemical imbalances or other proposed neurochemical substrates of disorders [e.g., 27]. Understanding the limits of scientific understanding paves the way for an informed choice about treatment options.

\subsection{Patients Have a Right to Be Treated with Psychosocial Interventions Alone If They So Choose}

Based on recent reviews of the evidence regarding the efficacy and safety of psychiatric medications, a risk/ benefit analysis suggests that psychotherapy be considered first, depending on patient preferences $[9,10]$. Patients, therefore, have a right to be treated by a physician who sees psychosocial options as viable first line, stand alone treatments (including psychotherapy, exercise and nutrition, problem solving, community, spiritual, and peer options) for emotional and behavioral problems. For example, in the case of depression, contrary to conventional wisdom, psychological treatments have been shown to be as effective as medication treatments in the short run with more durable benefits in the long run, especially when patient rated measures are considered, even if the depression is severe [28-30]. Combined treatments have not consistently fared better than psychological treatments alone over long term outcome but they have tended to have better results than medication treatment alone [31-34].

\subsection{Patients Have a Right to Be Exposed to the Lowest Risk of Adverse Events from Psychotropic Medications-A Right to a “First Do No Harm Approach"}

Since we are unaware of any scientific studies addressing the combination of more than two psychotropic medications [35] with adults (or more than one with children), this should be the upper limit. Even two medication combinations have been rarely studied, and when they have, underwhelming results seem the norm. For example, "treatment resistant depression" prompted the STAR*D (Sequenced Treatment Alternatives to Relieve Depression), a study that examined the impact of augmentation or medication switching strategies for depresssion when a traditional regimen of a single SSRI failed
[36]. The average remission rate (which was less than the traditional placebo response) based on the primary outcome measure was 28\% (Level 1 -initial regimen of a single SSRI) and 25\% (Level 2-patients augmented or switched), or a total remission rate of $39 \%$ when considering those who remitted at both levels together out of a total of 2876 participants. A more stringent perspective would take each level as a different treatment episode, resulting in an average remission rate of $27 \%$ across levels. Moderate to intolerable adverse events were experienced by $28 \%$ of participants at Level 1 [37] and $51 \%$ at Level 2 [38,39]. In addition, overall results from the large scale Combining Medications to Enhance Depression Outcomes (CO-MED) [40] study showed that a single antidepressant produced the same remission rate as combined antidepressants and that therapy with 2 medications resulted in more adverse events.

Prescribing psychotropics without FDA or other governing body approval, so called off-label prescribing should also be rare. Although polypharmacy and off label prescriptions of psychotropics tend to expose patients to increased risks and side effects, such practices have become increasingly popular, particularly in vulnerable populations of children and the elderly [12,41]. For example, a study of 11,700 youth covered by Medicaid found that the number of children newly treated with antipsychotics increased from 1482 in 2001 to 3110 in 2005 [42]. This means that $26 \%$ of these youth were taking antipsychotics in 2005, suggesting many off label prescriptions. Other studies have found that children covered by Medicaid were prescribed antipsychotics at a rate four times higher than children with private insurance, were more likely to receive antipsychotics for unapproved uses, and were more likely to receive multiple medications [43,44], despite the fact that not one randomized clinical trial to our knowledge has examined polypharmaceutical intervention with children. Poor children, apparently, are vulnerable to psychotropics used as interventions of control rather than therapy.

Finally, patients have a right for psychotropic medications to be used as primarily a short term treatment. Most of the scientific psychiatric database consists of controlled studies of 6 to 12 weeks in duration $[8,45]$. There are not enough controlled investigations beyond 12 weeks to guide patients or prescribers in terms of safety and efficacy. When longer trials are done, results are unimpressive. For example, the STAR*D reported that $58 \%$ of those who responded through the four levels relapsed at one year follow-up [38]. In a large scale investtigation of antipsychotics with adults with schizophrenia, $74 \%$ of participants discontinued before 18 months, largely due to inefficacy and intolerable side effects [46]. Finally, a study of antipsychotics with youth diagnosed with 
schizophrenia reported that only $12 \%$ of youth both responded and stayed on antipsychotics for a year [47]. Long term use of psychotropics does not appear to be empirically supported.

\subsection{Patients Have a Right to Monitor Their Treatment Response with Patient Rated Outcome Measures}

Clinicians and patients often differ substantially in their judgment of improvement in clinical trials [44]. A metaanalysis of 22 antidepressant studies $(\mathrm{N}=2230)$ found that antidepressants showed an approximate 20\% advantage over placebo on clinician-rated measures, but none on patient-rated measures [48]. This is the rule rather than the exception [21,49]. The lack of endorsement of efficacy by patients in clinical trials begs the question: If patients don't notice advantage over placebo, how significant can the advantage rated by others be?

Using patient rated measures of treatment response not only in clinical trials but also in practice will allow more accurate assessment of medication benefit and may even improve outcomes. Incorporating patient-rated outcomes into treatment, for example, has been found to signifycantly improve outcomes in psychotherapy, allowing the clinician to tailor intervention based upon patient response [14,50]. Monitoring treatment outcomes would allow patients to change treatment approaches if any given treatment was not working after a reasonable period of time.

In the absence of benefit, patients also have a right not to have their dosage increased. There appears to be a weak dose response relationship with psychotropic medications. Response does not typically improve with doses higher than those already in the recommended therapeutic range, for example, with antidepressants [51,52]. However, side effects and the risk of adverse events significantly increase with higher doses. Finally, patients have a right to be tapered off ineffective medications before additional medications are prescribed given that augmentation studies have shown limited benefits. In other words, patients have a right to experience a medication free period to see if they feel better before a new medication is added.

\subsection{Patients Have a Right to Untainted Scientific Data Conveyed in a Consumer Friendly Way Regarding Psychotropic Medication}

This would require a publicly accessible database of all published and unpublished data, as well as a straightforward presentation of the risks and benefits free of spin and marketing [53]. Unfortunately our scientific database appears to be distorted by ghost written articles and skewed by publication bias, i.e., publishing studies that are favorable to the pharmaceutical industry products [54,55], sometimes recasting unfavorable outcomes into the conclusion that the medication is "efficacious, safe, and well tolerated." Until an unvarnished database that includes all the data (including raw data) becomes available, the Cochrane database may serve as the best resource.

\section{A Higher Standard of Psychotropic Prescriptive Care}

- Prescribers should secure patient informed consent after full disclosure of the risks and benefits of psychotropic prescription [7].

- Psychosocial options, including psychotherapy, should be tried first consistent with patient preference.

- Practices that are not empirically supported—off label prescribing, polypharmacy (especially with children), dosages outside recommended ranges, and lifetime regimens - should be limited and include full patient consent as well as close monitoring.

- Patient rated measures of outcome should be used in both research and practice.

- Pharmaceutical company influence should be separated from science and practice.

- A data base of the risks and benefits of psychotropics, independent of industry influence, should be available to prescribers and patients.

\section{Conclusions}

The methodology of medication trials needs wholesale reform to address inherent flaws: analysis to detect penetration of the double blind and/or the use of psychoactive placebos; use of patient rated measures; long term evaluation of efficacy and safety; inclusion of investigators without pharmaceutical company affiliations; and independent reporting of the findings to remove marketing spin. Regarding practice, untainted information should be made available to prescribers of psychotropics. Pharmaceutical company press releases and "detailing" from sales representatives should include independent evaluation of claims as well as non-medication options. Incentives and benefits to prescribers should be eliminated. Psychosocial interventions have neither marketing representatives nor budgets and therefore a more concerted effort to include them is needed.

The $\mathrm{STAR}^{*} \mathrm{D}$ is but one example that demonstrates the need for straightforward reporting of the clinical trial evidence so that physicians can discern science from spin and draw their own conclusions. The STAR*D investigators posited a $67 \%$ cumulative remission rate but qualified that the estimate: “... assumes no dropouts, and it assumes that those who exited the study would have had the same remission as those who stayed in the pro- 
tocol” [38]. As the 67\% figure is often repeated while the unrealistic assumptions on which it is based are forgotten, it is easy for prescribers to conclude that augmentation/ switch strategies are soundly supported. On the other hand, if one looks at the remission across all levels, which at each level was quite meager and less than typical placebo response, combined with a 51\% adverse reaction profile after augmentation/switch, and a 58\% relapse rate, a different conclusion would likely result [10, 56]. A more stringent perspective reveals that after a year of continuation treatment following remission, of the 4041 patients who entered the program only 108 (3\%) had a sustained remission-all the other patients either dropped out or relapsed [38].

The unprecedented promotion of the pharmaceutical industry that targets all players in health care forms the basis of pharmacology's growing centrality in psychiatric treatment. While some patients may be helped with this focus, it misdirects primary care away from a safer intervention with comparable efficacy-psychotherapy, as well as other community-based, culturally sensitive options. Additionally, it promotes prescriptive treatments of questionable sustainability, fraught with potentially dangerous effects.

This article proposed a patient bill of rights and psychotropic prescription guidelines that embody a higher standard of care, making the patient a partner in the selection and administration of treatment. Such a collaboration allows the integration of the best research evidence with clinical expertise and patient values $[57,58]$. The proposed higher standard of care aligns the prescriber with the patient, the evidence, and the outcome of intervention, and perhaps more importantly, the commitment to first do no harm [59]. We believe that a careful reading of the 6 rights identified in this article will reveal them to reflect a scientifically supported, common sense, practical, and respectful approach to the use of psychotropic medications.

\section{REFERENCES}

[1] M. N. Stagnitti, "Trends in the Use and Expenditures for the Therapeutic Class Prescribed Psychotherapeutic Agents and All Subclasses, 1997 and 2004,” Agency for Healthcare Research and Quality, Rockville, 2007. http://www.meps.ahrq.gov/mepsweb/data_files/publicatio ns/st163/stat163.pdf.

[2] IMS Institute for Healthcare Informatics, "The Use of Medicines in the United States: Review of 2010,” IMS Institute for Healthcare Informatics, Norwalk, 2011. http://www.imshealth.com/deployedfiles/imshealth/Globa 1/Content/IMS\%20Institute/Static\%20File/IHII_UseOfMe d_report.pdf

[3] M. Olfson and S. C. Marcus, "Current Trends in Outpatient Psychotherapy,” American Journal of Psychiatry,
Vol. 167, 2010, pp. 1456-63. doi:10.1176/appi.ajp.2010.10040570

[4] B. G. Case, M. Olfson, S. C. Marcus and C. Siegel, "Trends in the Inpatient Mental Health Treatment of Children and Adolescents in U. S. Community Hospitals between 1990 and 2000," Archives of General Psychiatry, Vol. 64, No. 1, 2007, pp. 89-96. doi:10.1001/archpsyc.64.1.89

[5] M. Angell, "Medication Companies and Doctors: A Story of Corruption,” New York Times Review of Books, 2009. http://www.nybooks.com/articles/archives/2009/jan/15/m edication-companies-doctorsa-story-of-corruption/?page= 1)

[6] D. O. Antonuccio, W. G. Danton and T. M. McClanahan, "Psychology in the Prescription Era: Building a Firewall between Marketing and Science,” American Psychologist, Vol. 58, 2003, pp. 1028-1043. doi:10.1037/0003-066X.58.12.1028

[7] D. Cohen and D. Jacobs, “A Model Consent Form for Psychiatric Drug Treatment,” Journal of Humanistic Psychology, Vol. 40, No. 1, 2000, pp. 59-64. doi:10.1177/0022167800401006

[8] J. Sparks and B. Duncan, "Do No Harm: A Critical Risk/Benefit Analysis of Child Psychotropic Medications,” Journal of Family Psychotherapy, Vol. 19, No. 1, 2008, pp. 1-19. doi:10.1080/08975350801904072

[9] R. Brown, D. O. Antonuccio, G. DuPaul, M. Fristad, C. King, J. Piacentini and B. Vitiello, "Childhood Mental Health Disorders: Evidence Base and Contextual Factors for Psychosocial, Psychopharmacological, and Combined Interventions,” American Psychological Association, Washington, 2008. doi:10.1037/11638-000

[10] J. Sparks, B. Duncan, D. Cohen and D. Antonuccio, "Psychiatric Medications and Common Factors: An Evaluation of Risks and Benefits for Clinical Practice,” In: B. Duncan, S. Miller, B. Wampold and M. Hubble, Eds., The Heart and Soul of Change: Delivering What Works in Therapy, American Psychological Association, Washington, 2010, pp. 199-236. doi:10.1037/12075-007

[11] L. E. Beutler and M. L. Malik, "Rethinking the DSM," American Psychological Association, Washington, 2002. doi:10.1037/10456-000

[12] M. Piasecki and D. O. Antonuccio, “The DSM Debate: Potential Harms Related to Psychiatric Diagnosis,” Bulletin of the Association of the Advancement of Philosophical Psychiatry, Vol. 17, 2010, pp. 15-18.

[13] L. E. Beutler and M. L. Malik, "Diagnosis and Treatment Guidelines: The Example of Depression,” In: L. E. Beutler and M. L. Malik, Eds., Rethinking the DSM, American Psychological Association, Washington, 2002, pp. 252278. doi:10.1037/10456-010

[14] B. L. Duncan, “On Becoming a Better Therapist,” American Psychological Association, Washington, 2010.

[15] C. Hoge, J. Auchterlonie and C. Milliken, "Mental Health Problems, Use of Mental Health Services, and Attrition from Military Service after Returning from Deployment to Iraq or Afghanistan,” Journal of the American Medical 
Association, Vol. 295, No. 9, 2006, pp. 1023-1032. doi:10.1001/jama.295.9.1023

[16] J. Cape, C. Whittington, M. Buszewicz, P. Wallace and L. Underwood, "Brief Psychological Therapies for Anxiety and Depression in Primary Care: Meta-analysis and Metaregression,” BMC Medicine, Vol. 8, 2010, p. 38. doi:10.1186/1741-7015-8-38

[17] D. Healy, "The Latest Mania: Selling Bipolar Disorder," PLoS Medicine, Vol. 3, No. 4, 2006, p. 185. doi:10.1371/journal.pmed.0030185

[18] C. Moreno, G. Laje, C. Blanco, G. Huiping, A. B. Schmidt and M. Olfson, "National Trends in the Outpatient Diagnosis and Treatment of Bipolar Disorder in Youth," Archives of General Psychiatry, Vol. 64, No. 9, 2007, pp. 1032-1039. doi:10.1001/archpsyc.64.9.1032

[19] D. O. Antonuccio, "Treating Depressed Children with Antidepressants: More Harm than Benefit?” Journal of Clinical Psychology in Medical Settings, Vol. 15, No. 2, 2008, pp. 92-97. doi:10.1007/s10880-008-9108-9

[20] Treatment for Adolescents with Depression Study (TADS) Team, "Fluoxetine, Cognitive-Behavioral Therapy, and Their Combination for Adolescents with Depression," Journal of the American Medical Association, Vol. 292, No. 7, 2004, pp. 807-820. doi:10.1001/jama.292.7.807

[21] The TADS Team, “Treatment for Adolescents with Depression Study (TADS) Team, "Long-Term Effectiveness and Safety Outcomes," Archives of General Psychiatry, Vol. 64, No. 10, 2007, pp. 1132-1144. doi:10.1001/archpsyc.64.10.1132

[22] J. C. Fournier, R. J. DeRubeis, S. D. Hollon, S. Dimidjian, J. D. Amsterdam, R. C. Shelton, et al., "Antidepressant Medication Effects and Depression Severity: A Patient-level Meta-analysis," Journal of the American Medical Association, Vol. 303, No. 1, 2007, pp. 47-53. doi:10.1001/jama.2009.1943

[23] I. Kirsch, B. Deacon, T. Huedo-Medina, A. Scoboria, T. Moore and B. Johnson, "Initial Severity and Antidepressant Benefits: A Meta-Analysis of Data Submitted to the Food and Medication Administration," PLoS Medicine, Vol. 5, No. 2, 2008, p. 45.

[24] G. Andrews, "Should Depression Be Managed as a Chronic Disease?” British Medical Journal, Vol. 322, No. 7283, 2001, pp. 419-421. doi:10.1136/bmj.322.7283.419

[25] M. A. Posternak and I. Miller I, "Untreated Short-Term Course of Major Depression: A Meta-Analysis of Outcomes from Studies Using Wait-list Control Groups," Journal of Affective Disorders, Vol. 66, No. 2-3, 2001, pp. 139-146. doi:10.1016/S0165-0327(00)00304-9

[26] B. Duncan, S. Miller, J. Sparks, G. Jackson, R. Greenberg and K. Kinchin, “The Myth of the Magic Pill,” In: B. Duncan, S. Miller and J. Sparks, Eds., The Heroic Client, Jossey-Bass, San Francisco, 2004, pp. 147-177.

[27] J. Lacasse and J. Leo, "Serotonin and Depression: A Disconnect between the Advertisements and the Scientific Literature,” PloS Medicine, Vol. 2, No. 12, 2005, p. 392.

[28] D. O. Antonuccio, W. G. Danton and G. DeNelsky,
"Psychotherapy vs. Medication for Depression: Challenging the Conventional Wisdom with Data," Professional Psychology, Vol. 26, No. 6, 1995, pp. 574-585.

[29] R. J. DeRubeis, S. D. Hollon, J. D. Amsterdam, R. C. Shelton, P. R. Young, R. M. Solomon, et al., "Cognitive Therapy vs. Medications in the Treatment of Moderate to Severe Depression,” Archives of General Psychiatry, Vol. 62, 2005, pp. 409-416. doi:10.1001/archpsyc.62.4.409

[30] S. D. Hollon, R. J. DeRubeis, R. C. Shelton, J. D. Amsterdam, R. M. Salomon, J. P. O’Reardon, et al., “Prevention of Relapse Following Cognitive Therapy vs. Medications in Moderate to Severe Depression," Archives of General Psychiatry, Vol. 62, No. 4, 2005, 417-422.

[31] D. O. Antonuccio, D. Burns and W. G. Danton, "Antidepressants: A Triumph of Marketing over Science?” Prevention and Treatment, Vol. 5, No. 1, 2002.

[32] M. B. J. Blom, K. Jonker, E. Dusseldorp, P. Spinhowen, E. Hoencamp, J. Haffmans and R. van Dyck, "Combination Treatment for Acute Depression Is Superior Only When Psychotherapy Is Added to Medication,” Psychotherapy and Psychosomatics, Vol. 76, No. 5, 2007, pp. 289-297. doi:10.1159/000104705

[33] S. Dimidjian, S. Hollon, K. Dobson, K. Schmaling, R. Kohlenberg, M. Addis, et al., "Randomized Trial of Behavioral Activation, Cognitive Therapy, and Antidepressant Medication in the Acute Treatment of Adults with Major Depression,” Journal of Consulting and Clinical Psychology, Vol. 74, No. 4, 2006, pp. 658-670. doi:10.1037/0022-006X.74.4.658

[34] K. Dobson, S. Hollon, S. Dimidjian, K. Schmaling, R. Kohlenberg, R. Gallop, et al., "Randomized Trial of Behavioral Activation, Cognitive Therapy, and Antidepressant Medication in the Prevention of Relapse and Recurrence in Major Depression,” Journal of Consulting and Clinical Psychology, Vol. 76, No. 3, 2008, pp. 468-477. doi:10.1037/0022-006X.76.3.468

[35] C. Yury, J. Fisher, D. O. Antonuccio, M. Valenstein and J. Matuszak, "Meta-analysis of Antidepressant Augmentation: Piling on in the Absence of Evidence," Ethical Human Psychology and Psychiatry, Vol. 11, No. 3, 2009, pp. 171-182. doi:10.1891/1559-4343.11.3.171

[36] A. J. Rush, M. H. Trived, S. R. Wisniewski, J. W. Stewart, A. A. Nierenberg, M. E. Thase, et al., "Bupropion-sr, Sertraline, or Venlafaxine-xr after Failure of SSRIs for Depression,” New England Journal of Medicine, Vol. 354, No. 12, 2006, pp. 1231-1242. doi:10.1056/NEJMoa052963

[37] M. H. Trivedi, A. J. Rush, S. R. Wisniewski, A. A. Nierenberg, D. Warden, L. Ritz, et al., "Evaluation of Outcomes with Citalopram for Depression Using Measurement-based Care in STAR*D: Implications for Clinical Practice,” American Journal of Psychiatry, Vol. 163, No. 1, 2006, pp. 28-40. doi:10.1176/appi.ajp.163.1.28

[38] A. J. Rush, M. H. Trivedi, S. R. Wisniewsk, A. A. Nierenberg, J. W. Stewart, D. Warden, et al., “Acute and Longer-Term Outcomes in Depressed Outpatients Requiring One or Several Treatment Steps: A STAR*D Report,” American Journal of Psychiatry, Vol. 163, No. 5-7, 
2006, pp. 1905-1917. doi:10.1176/appi.ajp.163.11.1905

[39] M. H. Trivedi, M. Fava, S. R. Wisniewski, M. E. Thase, F. Quitkin, D. Warden, et al., "Medication Augmentation after the Failure of SSRIs for Depression,” New England Journal of Medicine, Vol. 354, No. 12, 2006, pp. 12431252. doi:10.1056/NEJMoa052964

[40] J. Rush, H. Madhukar, M. Trivedi, J Stewart, A. Nierenberg, M. Fava, et al., "Combining Medications to Enhance Depression Outcomes (CO-MED): Acute and Long-Term Outcomes of a Single-Blind Randomized Study," American Journal of Psychiatry, Vol. 168, No. 7, 2011, pp. 689-701. doi:10.1176/appi.ajp.2011.10111645

[41] J. A. Sparks and B. L. Duncan, "Critical Ethical Practice and Pediatric Antipsychotics,” In: S. Olfman and B. D. Robbins, Eds., Medicating Our Children, Praeger Publishers, Westport, in Press.

[42] P. Pathak, D. West, B. C. Martin, M. E. Helm and C. Henderson, "Evidence-based Use of Second-generation Antipsychotics in a State Medicaid Pediatric Population, 2001-2005,” Psychiatric Services, Vol. 61, No. 2, 2010, pp. 123-129. doi:10.1176/appi.ps.61.2.123

[43] S. Crystal, M. Olfson, C. Huang, H. Pincus and T. Gerhard, "Broadened Use of Atypical Antipsychotics: Safety, Effectiveness, and Policy Challenges," Health Affairs, Vol. 28, No. 5, 2009, pp. 770-781. doi:10.1377/hlthaff.28.5.w770

[44] J. Zito, D. Safer, D. Sai, J. Gardner, D. Thomas, P. Coombes, et al., "Psychotropic Medication Patterns among Youth in Foster Care,” Pediatrics, Vol. 121, No. 1, 2009, pp. 157- 163. doi:10.1542/peds.2007-0212

[45] S. Fisher and R. P. Greenberg, "From Placebo to Panacea: Putting Psychiatric Medications to the Test,” Wiley, New York, 1997.

[46] J. A. Lieberman, T. S. Stroup, J. P. McEvoy, M. S. Swartz, R. A. Rosenheck, O. Perkins, et al., "Effectiveness of Antipsychotic Medications in Patients with Chronic Schizophrenia," New England Journal of Medicine, Vol. 353, 2005, pp. 1209-1223. doi:10.1056/NEJMoa051688

[47] R. Findling, J. Johnson, J. McClellan, J. Frazier, B. Vitiello, R. Hamer, et al., "Double-Blind Maintenance Safety and Effectiveness Findings from the Treatment of Early-Onset Schizophrenia Spectrum (TEOSS) Study," Journal of the American Academy of Child and Adolescent Psychiatry, Vol. 49, No. 6, 2010, pp. 583-594.

[48] R. P. Greenberg, R. F. Bornstein, M. D. Greenberg and S. Fisher, "A Meta-Analysis of Antidepressant Outcome under "Blinder" Conditions," Journal of Consulting and Clinical Psychology, Vol. 60, No. 5, 1992, pp. 664-669.

\section{doi:10.1037/0022-006X.60.5.664}

[49] J. N. Jureidini, C. J. Doecke, P. R. Mansfield, M. M. Haby, D. B. Menkes and A. L. Tonkin, "Efficacy and Safety of Antidepressants for Children and Adolescents," British Medical Journal, Vol. 328, No. 7444, 2004, pp. 879-883. doi:10.1136/bmj.328.7444.879

[50] M. Lambert, "Yes, It Is Time for Clinicians to Routinely Monitor Treatment Outcome,” In: B. Duncan, S. Miller, B. Wampold, and M. Hubble, Eds., The Heart and Soul of Change: Delivering What Works in Therapy, American Psychological Association, Washington, 2010, pp. 239268. doi:10.1037/12075-008

[51] D. O. Antonuccio, D. W. Danton, G. Y. DeNelsky, R. P. Greenberg and J. S. Gordon, "Raising Questions about Antidepressants," Psychotherapy and Psychosomatics, Vol. 68, No. 1, 1999, pp. 3-14. doi:10.1159/000012304

[52] I. Kirsch, T. Moore, A. Scoboria and S. Nichols, “The Emperor's New Medications: An Analysis of Antidepressant Medication Data Submitted to the U.S. Food and Medication Administration," Prevention and Treatment, Vol. 3, 2002.

[53] D. O. Antonuccio and D. Healy, “The Researcher's Credo,” British Medical Journal, Vol. 336, No. 7645, 2008, p. 629. doi:10.1136/bmj.39520.521146.3A

[54] E. H. Turner, A. M. Matthews, E. Linardatos, R. A. Tell and R. Rosenthal, "Selective Publication of Antidepressant Trials and Its Influence on Apparent Efficacy," New England Journal of Medicine, Vol. 358, No. 3, 2008, pp. 252-260. doi:10.1056/NEJMsa065779

[55] B. Wieseler, N. McGaura and T. Kaiser, "Finding Studies on Reboxetine: A Tale of Hide and Seek," British Medical Journal, Vol. 341, 2010, p. 4942. doi:10.1136/bmj.c4942

[56] H. E. Pigott, A. M. Leventhal, G. S. Alter and J. J. Boren, "Efficacy and Effectiveness of Antidepressants: Current Status of Research," Psychotherapy and Psychosomatics, Vol. 79, No. 5, 2009, pp. 267-279. doi:10.1159/000318293

[57] APA Presidential Task Force on Evidence-Based Practice, "Evidence-Based Practice in Psychology," American Psychologist, Vol. 61, 2006, pp. 271-285.

[58] D. L. Sackett, W. M. Rosenberg, J. A. Gray, R. B. Haynes and W. S. Richardson, "Evidence Based Medicine: What It Is and What It Isn't,” British Medical Journal, Vol. 312, No. 7023, 1996, pp. 71-72.

[59] C. M. Smith, "Origin and Uses of Primum Non NocereAbove All, Do No Harm!” Journal of Clinical Pharmacology, Vol. 45, No. 4, 2005, pp. 371-377. doi:10.1177/0091270004273680 